\title{
PERBANDINGAN RERATA BESARAN LEEWAY SPACE SUKU BANJAR DENGAN RERATA LEEWAY SPACE MENURUT PROFFIT (Studi Analitik Observasional Radiografi Periapikal pada Masa Gigi Bercampur)
}

Gusti Meidy L*, Fajar Kusuma D.K. ${ }^{* *}$, Irnamanda D.H. ${ }^{* *}$

\begin{tabular}{c}
\hline Keywords: \\
Banjarese population, \\
leeway space
\end{tabular}

\section{ABSTRACT}

Background: Leeway space is an excess space available because of the differences between the amount of mesiodistal width of canine, first premolar and second premolar and the amount of mesiodistal width of primary canine, first molar and second molar. There's a variation of Leeway space among individuals. This variation occurs because of growth and development period which are influenced by environmental factors, nutrition and ethnic variations.

Purpose: The purpose of this study was to determine the difference in the average Leeway space of Banjarese population with the size of Leeway space according to Proffit.

Method: This study used an observational analytic with cross sectional approach. The number of mesiodistal width of primary $\mathrm{c}, \mathrm{m} 1$, and $\mathrm{m} 2$ is substracted with the number of mesiodistal width of permanent $C, P 1$, and P2 of 77 samples to determine the average Leeway space and then compared with the Leeway space according to Proffit. Measurements were done using a digital caliper followed with data analysis using Mann-Whitney test.

Result: The average of Banjarese population Leeway space is $0.37 \mathrm{~mm}$ in each region of the maxilla and $2.2 \mathrm{~mm}$ in each region of the mandible. Results of the Mann-Whitney test showed that there were significant differences in maxillary Leeway space of Banjarese population compared to the Leeway space according to Proffit.

Conclusion: The conclusion of this study is there were differences between the average Leeway space of Banjarese population with the Leeway space according to Proffit.

\section{PENDAHULUAN}

Profil wajah setiap ras dari negara-negara di penjuru dunia memiliki perbedaan. Elfiah (2011) berpendapat, pada penelitian variasi antropometri wajah Indonesia dengan pemeriksaan antropometri dan sefalometri, bahwa secara umum profil wajah orang Indonesia yang merupakan ras DeutroMelayu, baik profil skeletal dan jaringan lunak, lebih cembung dibandingkan ras atau etnis lain seperti Jepang, Cina dan Kaukasia. Kecembungan wajah orang Indonesia ini kemungkinan behubungan dengan retrusi wajah bagian tengah dan protrusi rahang atas, adanya inklinasi akar gigi anterior yang lebih protrusif serta adanya resesi dari dagu ${ }^{1}$. Perabuwijaya (2007), dalam penelitian konveksivitas wajah jaringan lunak ras DeutroMelayu, menyatakan bahwa nilai konveksivitas wajah jaringan lunak pria ras Deutro-Melayu tidak berbeda secara signifikan dengan ras Kaukasoid².

Secara umum, suku bangsa Indonesia ditentukan mengikuti garis paternalistik (ayah/ laki-laki), misalnya Suku Jawa dan Suku Batak. Laki-laki Suku Batak akan memberikan keturunan yang juga bersuku Batak. Walaupun

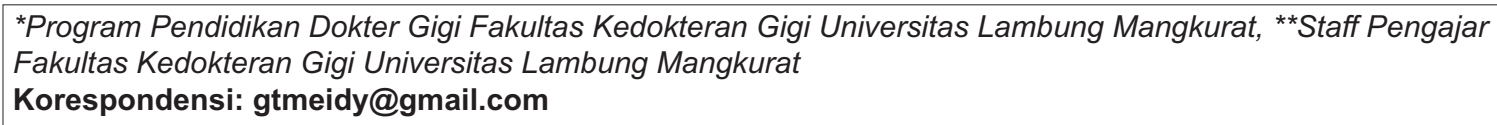


demikian terdapat beberapa suku bangsa Indonesia yang mengikuti garis maternalistik (ibu/perempuan) seperti Suku Minangkabau³

Salah satu suku yang mengikuti kedua garis paternalistik dan maternalistik adalah Suku Banjar. Suku Banjar ialah penduduk asli yang mendiami sebagian besar wilayah Kalimantan Selatan. Suku Banjar memiliki kesamaan dengan penduduk Pulau Sumatera dan daerah sekitarnya. Penduduk Pulau Sumatera dan daerah sekitarnya berpindah ke kawasan Kalimantan Selatan lebih dari seribu tahun silam. Penduduk asal setempat dinamakan secara umum sebagai Suku Dayak .

Daerah Kalimantan Selatan (daerah Banjar) yang memanjang dari Tanjung Selatan (ujung Selatan pulau Kalimantan) sampai dengan Kabupaten Tanjung merupakan melting-pot masyarakat yang membentuk suku bangsa Banjar. Orang-orang tersebut merupakan suku bangsa Maayan, Lawangan dan Bukit yang mengalami proses pembudayaan dan pencampuran darah dengan suku bangsa Melayu, Jawa dan Bugis, sehingga terbentuklah suku bangsa Banjar. Penduduk daerah Kalimantan Selatan disebut orang Banjar pada saat daerah Kalimantan Selatan berkembang menjadi Kesultanan Banjar. Istilah "orang Banjar" ini akhirnya meluas untuk menyebut semua penduduk yang memeluk agama Islam di daerah Kalimantan Selatan. Orang Dayak yang memeluk agama Islam juga menyebut dirinya "orang Banjar" 5 . Sistem kekerabatan masyarakat Suku Banjar ditentukan menurut garis ibu dan ayah atau bilateral ${ }^{6}$.

Penilaian awal untuk mengetahui diskrepansi panjang lengkung dapat dilakukan pada tahap gigi bercampur saat insisif permanen rahang bawah mulai tumbuh.
Analisis diagnosa komprehensif untuk diskrepansi panjang lengkung dapat dilakukan dengan mengevaluasi hubungan skeletal antara maksila dan mandibula, arah dan pola pertumbuhan, profil wajah, lebar wajah, keseimbangan otot dan gambaran pada dental dan oklusal termasuk posisi-posisi gigi, analisis panjang lengkung dan leeway space ${ }^{7}$. Rao (2012) menyatakan bahwa jumlah lebar mesiodistal gigi kaninus dan premolar pertama serta premolar kedua biasanya lebih kecil daripada jumlah lebar mesiodistal gigi kaninus dan molar pertama serta molar kedua sulung, kelebihan ruang tersebutlah yang disebut dengan Leeway space of Nance ${ }^{8}$.

Vyas dan Hantodkar (2011) berpendapat bahwa manajemen ruang dengan pemanfaatan leeway space merupakan salah satu aspek paling penting dalam perawatan ortodontik pada gigi bercampur berdasarkan potensinya untuk mencegah crowding pada gigi permanen ${ }^{9}$. Proffit (2014) menyatakan bahwa gigi molar sulung kedua rahang bawah ratarata $2 \mathrm{~mm}$ lebih besar dibandingkan dengan premolar kedua, dimana pada rahang atas, gigi molar sulung kedua 1,5 mm lebih besar. Gigi molar sulung pertama hanya sedikit lebih besar dari pada premolar pertama, tetapi memberi kontribusi $0,5 \mathrm{~mm}$ ruang lebih pada rahang bawah. Hasilnya adalah setiap sisi pada lengkung mandibula memiliki sekitar 2,5 $\mathrm{mm}$ leeway space, sedangkan pada lengkung maksila, ada sekitar $1,5 \mathrm{~mm}$ rata-rata ruang yang tersedia ${ }^{10}$.

Suatu penelitian di Zürich oleh Hille (2010) melaporkan bahwa ada perbedaan rerata leeway space pada perempuan dan laki-laki dibandingkan dengan penemuan sebelumnya ${ }^{11}$. Hasil dari penelitian-penelitian 
sebelumnya memperjelas bahwa leeway space berbeda pada setiap individu dan pada etnik atau suku tertentu.

\section{METODE PENELITIAN}

Penelitian ini merupakan jenis penelitian analitik observasional yang ditujukan untuk mencari rerata besaran leeway space pada Suku Banjar dan apakah ada perbedaan rerata leeway space pada Suku Banjar dengan leeway space menurut Proffit. Desain yang digunakan pada penelitian ini adalah cross sectional.

Populasi pada penelitian ini adalah masyarakat Suku Banjar dari umur 7-9 tahun yang bertempat tinggal di Banjarmasin. Teknik sampling yang digunakan adalah purposive sampling. Purposive Sampling adalah pengambilan sampel didasarkan pada kriteria yang telah ditetapkan baik kriteria inklusi maupun eksklusi. Inklusi dari sampel penelitian yaitu berumur 7-9 tahun, memiliki gigi bercampur, keturunan Suku Banjar (tiga keturunan yaitu kakek, nenek, ayah dan ibu dari sampel merupakan Suku Banjar), dapat membuka mulut dengan baik, tidak terdapat karies pada bagian proksimal, tidak infraoklusi, bersedia menjadi sampel, dan kooperatif. Sedangkan ekslusinya meliputi sampel dengan keturunan campuran antar dua atau lebih suku, umur lebih dari 9 tahun, gigi kaninus, molar pertama dan molar kedua sulung tidak ada atau karies proksimal, serta kakek, nenek, ayah ataupun ibu bukan Suku Banjar.

Semua sampel yang memenuhi syarat akan dijadikan sampel penelitian sampai jumlah sampel yang dibutuhkan terpenuhi berdasarkan waktu pengumpulan yang tersedia. Perhitungan sampel dengan rumus analitik numerik tidak berpasangan mendapatkan hasil minimal sampel sebanyak 77 sampel. Instrumen pada penelitian ini yaitu dengan menggunakan data diri subjek penelitian, consent, kaliper, alginat, gips stone, bowl dan spatula, sendok cetak dan foto radiografi periapikal. Variabel penelitian ini terdiri dari variabel bebas yaitu Suku Banjar dan variabel terikat yaitu rerata besaran Leewaay space.

Penelitian ini dilakukan di beberapa sekolah dasar di Banjarmasin dengan prosedur peneliti mendatangi sekolah tersebut. Kemudian peneliti melakukan pemilihan sampel yang sesuai dengan kriteria yang telah ditentukan. Pasien dan orang tua pasien diberikan form data diri subjek penelitian untuk diisi dan pasien yang dipilih sebagai sampel adalah pasien yang telah menyetujui prosedur penelitian dalam consent. Persetujuan harus diberikan oleh orang tua atau wali yang kompeten karena sampel masih di bawah umur dewasa yaitu 7-9 tahun yang mana menurut World Health Organization (WHO), batas usia anak adalah sejak dalam kandungan hingga usia 19 tahun. Pemeriksaan radiografi periapikal pada pasien dilakukan di Rumah Sakit Sari Mulia unit radiografi oral dan akan dilanjutkan dengan pencetakan rahang atas dan rahang bawah sampel untuk mendapatkan model studi agar dapat menganalisis efek distorsi radiografi dengan analisis Huckaba.

Pengumpulan data berupa hasil data diri sampel penelitian dan pemeriksaan klinis gigi sampel diperoleh langsung oleh peneliti dari subjek penelitian. Peneliti melakukan pengukuran secara inter-examiner terlebih dahulu (dilakukan oleh dua pengamat) untuk menguji keakuratan pengukuran, kemudian 
dilakukan uji-T berpasangan terhadap kedua hasil pengukuran untuk mengetahui apakah ada perbedaan pengukuran yang signifikan diantaranya. Data yang diperoleh, dimasukkan dalam tabel, kemudian dilakukan perhitungan dengan bantuan SPSS. Pengolahan data pertama yang dilakukan adalah editing yaitu memeriksa kembali data yang dikumpulkan, selanjutnya dilakukan tabulasi yaitu membuat tabel-tabel data dan yang terakhir melakukan perhitungan yaitu data yang didapatkan dari tabel dibuat dengan statistik analitik observasional.

Data rerata besaran leeway space pada Suku Banjar yang terukur dalam millimeter dievaluasi dengan melakukan uji normalitas Kolmogorov-Smirnov. Jika data terdistribusi normal, dilakukan analisis parametrik dengan uji $T$ tidak berpasangan. Jika data tidak terdistribusi normal, maka analasis data dilakukan dengan menggunakan uji Mann Whitney.

\section{HASIL PENELITIAN}

Penelitian untuk mengetahui perbandingan rerata besaran leeway space pada Suku Banjar dengan rerata leeway space Proffit menggunakan radiografi periapikal pada masa gigi bercampur telah dilakukan. Hasil penelitian yang telah dilakukan untuk mengetahui rerata leeway space pada Suku Banjar dapat dilihat pada tabel serta deskripsi berikut.

Uji reliabilitas inter-examiner pada lebar mesiodistal gigi $\mathrm{c}, \mathrm{m} 1$, dan $\mathrm{m} 2$ sulung serta C, P1, dan P2 dilakukan pada hasil pengukuran oleh dua orang observer. Hasil uji t berpasangan pada setiap gigi yang diukur menunjukan nilai korelasi $p>0,05$ yang mana dapat disimpulkan tidak ada perbedaan yang signifikan antara kedua pengukuran.

Rerata ukuran dari masing-masing

Tabel 1 Rerata ukuran lebar mesiodistal gigi $c, m 1$, dan $m 2$ sulung pada Suku Banjar

\begin{tabular}{ccccc}
\hline \multirow{2}{*}{$\begin{array}{c}\text { Gigi } \\
\text { Sulung }\end{array}$} & \multicolumn{2}{c}{$\begin{array}{c}\text { Rahang atas } \\
(\mathrm{mm})\end{array}$} & \multicolumn{2}{c}{$\begin{array}{c}\text { Rahang bawah } \\
(\mathrm{mm})\end{array}$} \\
\cline { 2 - 5 } & Kanan & Kiri & Kanan & Kiri \\
\hline $\mathrm{c}$ & 6,91 & 6,92 & 5,92 & 5,93 \\
m1 & 7,47 & 7,48 & 8,38 & 8,4 \\
$\mathrm{~m} 2$ & 9,5 & 9,47 & 10,79 & 10,8 \\
\hline
\end{tabular}

Tabel 2 Rerata ukuran lebar mesiodistal gigi $\mathrm{C}, \mathrm{P} 1$, dan $\mathrm{P} 2$ permanen pada Suku Banjar

\begin{tabular}{ccccc}
\hline \multirow{2}{*}{$\begin{array}{c}\text { Gigi } \\
\text { Permanen }\end{array}$} & \multicolumn{2}{c}{$\begin{array}{c}\text { Rahang atas } \\
(\mathrm{mm})\end{array}$} & \multicolumn{2}{c}{$\begin{array}{c}\text { Rahang bawah } \\
(\mathrm{mm})\end{array}$} \\
\cline { 2 - 5 } & Kanan & Kiri & Kanan & Kiri \\
\hline C & 8,31 & 8,32 & 7,22 & 7,23 \\
P1 & 7,74 & 7,75 & 7,79 & 7,8 \\
P2 & 7,49 & 7,55 & 7,68 & 7,7 \\
\hline
\end{tabular}

Hasil perhitungan perbandingan rerata besaran leeway space pada Suku Banjar dan leeway space Proffit dapat dilihat dari tabel berikut.

Tabel 3 Perbandingan rerata leeway
space pada Suku Banjar
dengan rerata leeway space
Proffit

\begin{tabular}{lcc}
\hline \multicolumn{1}{c}{ Leeway } & $\begin{array}{c}\text { Suku } \\
\text { Banjar } \\
(\mathrm{mm})\end{array}$ & $\begin{array}{c}\text { Proffit } \\
(\mathrm{mm})\end{array}$ \\
\hline Kanan atas & 0,375 & 1,5 \\
Kiri atas & 0,378 & 1,5 \\
Kanan bawah & 2,248 & 2,5 \\
Kiri bawah & 2,230 & 2,5 \\
\hline
\end{tabular}

Tabel di atas menunjukkan adanya perbedaan antara rerata ukuran leeway space 
Suku Banjar dengan leeway space Proffit dimana selisih perbedaan antara kedua leeway space tersebut adalah $1,125 \mathrm{~mm}$ pada rahang atas kanan, 1,122 $\mathrm{mm}$ pada rahang atas kiri, 0,252 $\mathrm{mm}$ pada rahang bawah kanan, dan $0,27 \mathrm{~mm}$ pada rahang bawah kiri. Hal tersebut menunjukkan bahwa ada perbedaan antara leeway space Suku Banjar dan leeway space Proffit.

Uji normalitas Kolmogorov-Smirnov dilakukan pada data penelitian karena jumlah sampel penelitian lebih dari 50 sampel. Nilai signifikansi dari hasi uji normalitas data adalah $p=0,050$ untuk rahang atas kanan dan $p=0,056$ $(p>0,05)$ untuk rahang atas kiri. Pada rahang bawah rahang bawah kanan dan kiri didapatkan $p=0,200 \quad(p>0,05)$ yang mana menunjukkan bahwa data penelitian terdistribusi normal.

Uji homogenitas dengan Levene's test didapatkan nilai $p<0,05$ pada seluruh regio dimana dapat disimpulkan bahwa data yang didapat tidak homogen.

Berdasarkan hasil uji homogenitas, data yang didapat tidak homogen maka selanjutnya dilakukan uji alternatif yaitu uji nonparametrik. Uji nonparametrik yang digunakan adalah Mann-Whitney. Hasil uji Mann-Whitney pada leeway space rahang atas bernilai $p=0,000$ $(p<0,05)$ pada kedua regio. Pada leeway space rahang bawah memperoleh nilai $p=0,011$ $(p<0,05)$ pada regio kanan dan pada regio kiri adalah $p=0,002(p<0,05)$. Hal ini menunjukan bahwa terdapat perbedaan yang bermakna antara leeway space pada setiap regio rahang atas dan rahang bawah Suku Banjar dengan Proffit.

\section{DISKUSI}

Bagian terpenting dari lengkung gigi dalam perkembangan inklusi adalah pada segmen premolar. Ini dikarenakan premolar yang erupsi berukuran lebih kecil secara signifikan dalam dimensi mesiodistal daripada gigi-gigi molar sulung yang digantikannya. Maka dari itu, perubahan besar dalam oklusi diobservasi selama premolar bererupsi. Kelebihan ruang karena perbedaan lebar mesiodistal gigi premolar yang lebih kecil dari pada gigi molar sulung yang digantikan oleh premolar disebut dengan Leeway space of Nance ${ }^{8,12}$.

Hasil penelitian pada tabel 3 terlihat bahwa leeway space rahang atas pada Suku Banjar adalah $0,75 \mathrm{~mm}$ yang mana berkisar $0,37 \mathrm{~mm}$ pada setiap region, sedangkan menurut Proffit, leeway space rahang atas dapat mencapai 1,5 $\mathrm{mm}$ disetiap regionya. Rerata leeway space pada rahang bawah Suku Banjar adalah 4,4 $\mathrm{mm}$ dengan ukuran kurang lebih 2,2 mm di setiap regio yang mana tidak berbeda jauh dengan leeway space Proffit yaitu $2,5 \mathrm{~mm}$. Penelitian sebelumnya menyatakan bahwa faktor lingkungan, nutrisi dan variasi etnik dapat mempengaruhi ukuran rerata leeways space $^{13}$. Hasil penelitian ini menyatakan bahwa adanya perbedaan yang bermakna antara leeway space Suku Banjar dengan leeway space Proffit. Perbedaan tersebut terdapat pada leeway space rahang atas Suku Banjar terhadap leeway space Proffit.

Ukuran mesiodistal pada gigi orang Kaukasia menurut McDonald (1998), jika dibandingkan dengan ukuran mesiodistal gigi yang didapat dari data penelitian (tabel 1 dan tabel 2), lebar mesiodistal gigi premolar pertama yang didapat dari data sampel adalah $\mathrm{mm}$ yang mana berukuran lebih besar dari ukuran menurut McDonald yaitu 7,00. Perbedaan ukuran tersebut juga terdapat pada lebar mesiodistal premolar kedua rahang 
atas yaitu $\mathrm{mm}$ dari data yang didapat dan $6,5 \mathrm{~mm}$ menurut McDonald. Maka dari itu, jika dibandingkan dengan orang Kaukasia, leeway space Suku Banjar yang merupakan ras Mongoloid cenderung lebih kecil ${ }^{14}$.

Terdapat perbedaan pada leeway space Suku Banjar apabila dibandingkan dengan leeway space menurut Proffit, terutama pada rahang atas. Penelitian ini didukung oleh penelitian yang juga dilakukan pada ras Mongoloid yaitu populasi di India yang mana ditemukan rerata ukuran leeway space pada rahang atas adalah sekitar 0,99 $\mathrm{mm}$ dan pada rahang bawah adalah 1,97 $\mathrm{mm}^{15}$. Maka dari itu, dapat dilihat dari perbandingan tersebut bahwa setiap ras ataupun suku memiliki rerata ukuran leeway space yang berbeda-beda.

Manajemen ruang dengan pemanfaatan leeway space merupakan salah satu aspek paling penting dalam perawatan ortodontik pada gigi bercampur berdasarkan potensinya untuk mencegah crowding pada gigi permanen ${ }^{8}$. Setiap individu memiliki ukuran leeway space yang berbeda. Hal tersebut dikarenakan periode pertumbuhan dan perkembangan dipengaruhi oleh faktor lingkungan, nutrisi dan variasi etnik ${ }^{12,16}$.

Ukuran Leeway space antara rahang atas dan rahang bawah dapat diketahui pada rahang atas lebih kecil dibandingkan dengan rahang bawah. Hal ini sesuai dengan penelitian Khanehmasjedi dan Bassir (2013) pada populasi Iran yang menyatakan bahwa ukuran kaninus dan premolar lebih besar pada rahang atas dibandingkan pada rahang bawah yang menyebabkan leeway space pada maksila lebih kecil. Sebagian besar dari leeway space di rahang atas digunakan oleh kaninus permanen yang biasanya $1 \mathrm{~mm}$ lebih lebar dari pendahulunya ${ }^{15}$.
Terjadinya crowding pada lengkung gigi didefinisikan sebagai kurangnya ruang untuk susunan gigi. Hal ini sering terjadi karena diskrepansi panjang lengkung dengan ukuran gigi. Variasi dalam ukuran gigi juga berhubungan dengan genetika (misalnya, jenis kelamin dan etnis) dan lingkungan sebagaimana leeway space sendiri. Meskipun mekanisme yang masih tidak jelas, gen yang mengontrol ukuran gigi juga berhubungan atau diwariskan dengan gen lain yang mengontrol pertumbuhan tulang rahang ${ }^{17}$.

Leeway space tidak tersedia jika jumlah dari ukuran mesiodistal gigi permanen yang belum tumbuh lebih besar daripada gigi desiduinya. Hal ini dikenal sebagai 'defisiensi leeway space' atau 'leeway space negatif'. Dalam kasus ini, gigi berjejal akan sering terjadi ${ }^{18}$.

Leeway space pada rahang atas Suku Banjar berukuran kurang dari $1 \mathrm{~mm}$ yaitu $0,37 \mathrm{~mm}$ pada setiap sisi sedangkan menurut Bishara (2001), kelebihan leeway space sebanyak $1 \mathrm{~mm}$ atau lebih akan lebih baik ${ }^{18}$. Ukuran tersebut lebih kecil dibandingkan leeway space ideal menurut Proffit (1,5 $\mathrm{mm}$ ), sehingga dapat disimpulkan bahwa berdasarkan leeway space ideal Proffit, Suku Bajar cenderung mengalami crowding pada rahang atas.

Hasil penelitian ini menyatakan bahwa kecilnya rerata leeway space pada rahang atas Suku Banjar dapat menjadi suatu indikasi untuk perawatan ortodontik sejak usia dini terutama pada masa gigi bercampur karena crowding dapat ditangani dengan pemanfaatan leeway space. Pengelolaan ruang selama perkembangan gigi penting untuk keseimbangan sistem stomatognatik. Fase perkembangan gigi dan beserta urutan erupsi, simetri, dan kronologi harus diketahui 
oleh praktisi, untuk mengelola leeway space untuk posisi yang tepat dari gigi permanen ${ }^{19}$.

\section{KESIMPULAN}

Berdasarkan hasil penelitian dapat disimpulkan bahwa rerata leeway space pada Suku Banjar pada rahang atas adalah sekitar $0,37 \mathrm{~mm}$ dan $2,2 \mathrm{~mm}$ pada rahang bawah di setiap region, terdapat perbedaan yang signifikan antara rata-rata leeway space Suku Banjar dan leeway space Proffit pada rahang atas. Leeway space rahang atas pada Suku Banjar berukuran lebih kecil jika dibandingkan dengan leeway space ideal Proffit. Potensi terjadinya crowding pada rahang atas Suku Banjar dapat dinilai cukup tinggi sehingga akan dibutuhkan space management dengan perawatan ortodontik. Persiapan rencana perawatan ortodontik pada Suku Banjar dapat dilakukan sejak dini misalnya dengan menggunakan space maintainer.

\section{DAFTAR PUSTAKA}

1. Elfiah U, Putri IL, Hutagalung MR, Perdanakusuma DS, Kosbandriati T. Variasi antropometri, wajah Indonesia dan sefalometri sebagai data dasar pada rekonstruksi trauma maksilofasial. Journal of Emergency. 2011; 1(1): 1-12.

2. Perabuwijaya B. Analisa konveksivitas wajah jaringan lunak secara sefalometri lateral pada mahasiswa Deutro-Melayu FKG USU usia 20-25 tahun (skripsi). Medan: Departemen Ortodonti Fakultas Kedokteran Gigi Universitas Sumatera Utara; 2007.

3. Na'im A, Syaputra H. Kewarganegaraan, suku bangsa, agama, dan bahasa sehari-hari penduduk Indonesia. Hasil sensus penduduk. Jakarta (Indonesia): Badan Pusat Statistik. 2010.

4. Aman R, Hamid Z, Hamid SA. Profil pemikiran Banjar: suatu kajian perbandingan antara suku Banjar di Malaysia dan di Indonesia. Malaysia Journal of Society and Space. 2012; 8: 12-22.

5. Sari SM, Melinda S. Aplikasi pengaruh Islam pada interior rumah bubungan tinggi di Kalimantan Selatan. Dimensi Interior. Desember 2004; 2(2): 121-133.
6. Ardhani F. Perbedaan kepuasan perkawinan pada wanita suku Bugis, Jawa, dan Banjar di kecamatan Balikpapan Selatan kota Balikpapan. eJournal Psikologi. 2015; 3(1): 358-368.

7. American Academy of Pediatric Dentistry. Guideline on management of the developing dentition and occlusion in pediatric dentistry. Reference manual. 1990; 36(6): 251-263.

8. Rao A. Principles and practice of pedodontics [e-book]. 3rd ed. New Delhi (India): Jaypee Brothers Medical Publishers (P) Ltd.; 2012. Available from: Google Books.

9. Vyas MB, Hantodkar N. Resolving mandibular arch discrepancy through utilization of leeway space. Contemp Clin Dent. 2011 Apr-Jun; 2(2): 115-118.

10. Proffit WR, Fields Jr HW, Sarver DM. Contemporary orthodontics [e-book]. 5th ed. St. Louis (Missouri): Mosby Elsevier; 2014. 101.

11. Hille HM. The mean leeway space in a population of orthodontic patients in Zurich. Zurich: Universitas Zurich; 2010.

12. Phulari RG. Textbook of dental anatomy, physiology and occlusion [e-book]. New Delhi (India): Jaypee Brothers Medical Publishers (P) Ltd.; 2014. 313-314.

13. Louly F, Nouer PRA, Janson G, Pinzan A. Dental arch dimensions in the mixed dentition: a study of Brazilian children from 9-12 years of age. J Appl Oral Sci. 2011; 19(2): 169-174.

14. Green-Thompson NF. Measuring and predicting leeway space in mixed dentition on panoramic $x$-rays using computer imaging analysis. Johannesburg: University of the Witwatersrand; 2007.

15. Tarvade SM, Agrawal GR, Daokar S. Mean leeway space in Indian population. Indian Journal of Basic and Applied Medical Research. June 2015; 4(3): 518-522.

16. Hudson APG, Harris AMP, Mohamed N, Joubert $\mathrm{J}$. Use of the passive lower lingual arch in the management of anterior mandibular crowding in the mixed dentition. SADJ. 2013 Apr; 68(3): 114-119.

17. Altherr ER, Koroluk LD, Phillips C. Influence of sex and ethnic tooth-size differences on mixed dentition space analysis. Am J Orthod Dentofacial Orthop. September 2007; 132(3): 332-339.

18. Bishara SE. Textbook of orthodontics [e-book]. Philadelphia (Pennsylvania): W. B. Saunders Company; 2001. 57.

19. Gallão S, Santos-Pinto LD, Santos-Pinto AD, Martins LP, Fahning A, Magno F, Jeremias F, Faltin RM . Space management during dentition development: a case report. J Health Sci Inst. 2010; 28(1): 87-88. 